\title{
Financial Inclusion and Virtual Bank in the Era of Digitalisation: A Regulatory Case Study in Hong Kong
}

https://doi.org/10.21272/sec.5(3).81-91.2021.

Sau-Wai Law, ORCID: https://orcid.org/0000-0002-5231-2845

Department of Law and Business, Hong Kong Shue Yan University, Hong Kong

\begin{abstract}
Implicit in the promise of virtual banks is the mission of promoting financial inclusion in Hong Kong, through offering increased accessibility and brand-new customer experiences through the internet which are said to be easier, more personalised and customer-centered. Nevertheless, while regulators encourage using technological solutions to reduce barriers to access and friction, there is a need to strike a balance between promoting technological innovations, protecting customers, and enhancing the returns to investors. Through the content analysis of the recent speeches and guidelines from Hong Kong Monetary Authority and the financial inclusion report from the United Kingdom, it is observed that the regulation of virtual banks in Hong Kong tends to focus predominately on promoting technological innovations. This is unlikely to be sufficient to replicate the trust and confidence in the traditional banking environments due to the lack of consideration to incorporate human factors between banks and clients. This paper articulates the importance of improving the following three areas which could be incorporated into future amendments to future regulatory guidelines: First is to review and accommodate the differences in the bank-customer relationship under the new interaction model. Second is to enhance transparency and disclosure of the technology involved in virtual bank operation. Third is to provide greater assistance to customers to improve their comprehensiveness of the increasing complexity of bank operation, particularly for those who do not have high financial literacy and those who might be discouraged from making an enquiry due to lack of human interaction with the banks. These would improve accessibility and make a meaningful impact to financial inclusion through the launch of virtual banks in Hong Kong.
\end{abstract}

Keywords: banking law and practices, financial regulation, financial inclusion, virtual banking, bank digitisation, digitalisation.

JEL Classification: E58.

Cite as: Sau-Wai Law (2021). Financial Inclusion and Virtual Bank in the Era of Digitalisation: A Regulatory Case Study in Hong Kong. SocioEconomic Challenges, 5(3), 81-91. https://doi.org/10.21272/sec.5(3).81-91.2021.

$\begin{array}{lll}\text { Received: 23.07.2021 Accepted: 07.09.2021 } & \text { Published: 13.09.2021 }\end{array}$

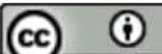

Copyright: (C) 2021 by the author. Licensee Sumy State University, Ukraine. This article is an open access article distributed under the terms and conditions of the Creative Commons Attribution (CC BY) license (https://creativecommons.org/licenses/by/4.0/).

\section{Introduction}

In recent years, as technology has continued to develop and permeate every aspect of our lives including banking, policy makers including the Hong Kong Money Authority have latched onto virtual banks as one of the ways to promote financial inclusion. Virtual banks serve to offer increased accessibility to bank services and brand-new customer experiences through the adoption of financial technology, and hence make banking service easier for bank customers to use, cheaper for banks to operate and provide a more personalised and "customer-centric" experience. Nevertheless, while regulators encourage using technological solutions to overcome barriers to access, lower fees, and reduce friction, they may come short on promoting financial inclusion. There is a need to strike a balance between promoting technological innovations, protecting customers, and enhancing the returns to investors. 
What is financial inclusion?

Broadly speaking, 'financial inclusion' is the policy solution or initiatives to the problem of 'financial exclusion'. Starting in the late 1990s, there has been increasing awareness and public debate about the problem of social exclusion which examines how poor and certain marginalised groups were unable to participate in social, economic, political, and cultural life due to their financial strength. One key aspect of that is financial exclusion, which refers to the unavailability or unaffordability of financial products and services to these segments of society (Gov.uk, 2017). Therefore, "Financial Inclusion" or "Inclusive Finance" refers to the making of financial products and services accessible and affordable to all individuals and businesses, regardless of their personal net worth or company size, by removing barriers that exclude people from participating in and using financial services.

Accessibility to financial services, from simple savings account to affordable credit to insurance, is a building block for both poverty reduction and opportunities for economic growth, and is thus recognised as important enabler for broader socio-economic development and participation in society (The World Bank, 2017). So much so that it is identified as a key enabler to 8 of the 17 UN Sustainable Development Goals (Sustainable Development Goal, 2021).

Globally, it is estimated that there are 1.7 billion people unbanked in 2017 (The World Bank, 2017), which means they have no access to basic financial services such as a savings account or electronic instrument to store money, to send and receive payments. Additionally, there is an even larger number of people estimated to be "underbanked", which means that while they have access to a bank account, they lack convenient access to affordable banking products and financial services, and hence need to rely on high-cost alternative financial services such as money orders, check-cashing services, and payday loans rather than on traditional loans and credit cards to manage their finances and fund purchases.

Hong Kong, however, is already one of the world's most banked populations. Approximately $95 \%$ of the population have a bank account (The World Bank, 2017), while Singapore is at 98\% and Mainland China is at around $80 \%$ (but skewered heavily towards the rich) (The World Bank, 2017). Nevertheless, in Hong Kong there are specific groups that are not well-served and/or are under-banked.

In the Hong Kong context, we believe there are three facets of financial exclusion:

i) those who lack access to basic banking services at all (that is, the unbanked). There are three groups of the Hong Kong public that fall into this category, the poor (who have 5\% lower rates of bank account ownership than the rich), the elderly and low-income retail customers (HKSAR, 2019);

ii) those who can access basic banking services, but lack access to other types of financial service products beyond basic banking facilities, such as loans and insurance (that is, the under-banked); and

iii) those who may already have access to banking, but face challenges that limit or reduce their access over time, such as due to high account keeping fees, overly difficult customer due diligence requirements (HKSAR, 2019), and difficulty in physical access such as wheelchair access to branches, availability of braille, documents in languages other than Chinese or English etc. These factors hinder general access to banking services and disproportionately impact the poor, elderly and low-income retail customers. As we will argue below, this group will include a growing number of people as a result of digital exclusion.

In a professional journal issued by the Hong Kong Institutes of Bankers, July/ August Issues (Law and Wong, 2021), I have co-authored an article which addresses five key issues driven under the above three facets. It offers a case in point to further investigate the following five key issues from a regulatory perspective, namely: (1) Exclusion arising from requirements on hardware, software, and technology literacy; (2) Emergence of cybersecurity risks; (3) Reconciliation of customers who prefer or require face-to-face services; (4) Customer perceptions of bank's commitment; and (5) Potential issues around the business model. This paper addresses further and articulates possible issues through laying down the findings of content analysis of relevant regulatory documents in Hong Kong and the UK. 


\section{Literature Review}

Accessibility to financial services, from simple savings account to affordable credit to insurance, is a building block for both poverty reduction and opportunities for economic growth, and thus is recognised as an important enabler for broader socio-economic development and participation in society. It is also identified as a key enabler to eight of the 17 UN Sustainable Development Goals (Sustainable Development Goal, 2021). Although Hong Kong is already one of the world's most banked populations (The World Bank, 2017), the Asian Development Bank has shown that Hong Kong is only ranked 37 out of 176 countries with a Financial Inclusion Index (FII) of 50.76, whilst Singapore ranked 25 (FII: 58.24) and China ranked 84 (FII: 30.22), while Spain ranked $1^{\text {st }}$ (FII: 90.98) (Park and Mercado, 2015). It indicates that in Hong Kong there are still groups that are under-served or under-banked under the three facets mentioned above. Those findings have two implications: first the need to unify the measurement of financial inclusion, and second the need to identify exclusion factors.

\section{How virtual banks can promote financial inclusion}

As technology, particularly the internet and smartphones, has changed every aspect of our lives, it has also changed the way we bank and increased the importance of banking.

With the growing digital economy, small and medium enterprises can now reach out to consumers directly, not just in the neighbourhood, but potentially around the world. While this brings a new world of opportunities to entrepreneurs, its reliance on digital financial services has led regulators and banks globally to explore the promise of digital technology and how it could further financial inclusion, in particular, around virtual banks.

In Hong Kong, the banking regulator, the Hong Kong Monetary Authority ("HKMA") defines a "virtual bank" as a bank which delivers retail banking services primarily, if not entirely, through the internet or other forms of electronic channels instead of physical branches (Hong Kong Monetary Authority, 2021).

Given that one of the largest expenses of any bank is the cost of establishing and maintaining a physical branch network, there is a clear opportunity here to exploit the promise of virtual banks to reduce costs. Indeed, it is one of the HKMA's stated primary objectives of introducing virtual banks into Hong Kong is to promote financial inclusion by leveraging their IT prowess to lower the incremental cost of taking on additional customers.

In this way, the HKMA has made a conscious policy choice to tie the destiny of the two together, when in 2017, it announced an intention to the local banking industry, to bring Hong Kong into "Smart Banking era" (second paragraph, Hong Kong Monetary Authority, 2019b). The HKMA has always had a thematic goal to promote financial inclusion, which it frames as being "how do we make sure the financial services industry serve the whole community, including those market segments that may be less profitable" (para 10, Hong Kong Monetary Authority, 2019c), and it is virtual banks that is giving the HKMA a new way to tackle an old problem. By allowing a limited number of new virtual banks into a heavily saturated market, but those with a different business model and lower cost structure that could profitably service a formerly unprofitable segment of the community thereby increasing financial inclusion.

It is for this reason that in the HKMA's Revised Guidelines, they have specified certain aspects to ensure virtual banks are, at least, accessible to these formerly unprofitable segments of the community. A key requirement on virtual banks is that they should not impose any minimum balance requirements or low-balance fees on customers (para 6, Hong Kong Monetary Authority, 2018). But otherwise, the approach to virtual banking is not very different to the licensing of traditional banks, as virtual banks are not subject to lower regulation, supervision, or levels of capital requirements. Virtual banks must still comply with fair dealing rules, abiding by the Treat Customers Fairly Charter and the Code of Banking Practice issued by Hong Kong Association of Banks / DTC Association. Indeed, the biggest (if not the only) difference is that they are allowed to operate without the need to maintain a physical branch network. In March 2019, the HKMA announced four new virtual banking licences, and since then another four have been announced bringing the total to eight licences - though not all have commenced operations. 
HKMA has put forth requirements to improve accessibility of virtual banks. For example, para 6 of the HKMA's Revised Guidelines on the Authorization of Virtual Banks has explicitly requires virtual banks should not impose any minimum account balance requirement or low-balance fees on their customers:

"Like conventional retail banks, virtual banks should play an active role in promoting financial inclusion in delivering their banking services. While virtual banks are not expected to maintain physical branches, they should endeavour to take care of the needs of their target customers, be they individuals or SMEs. Virtual banks should not impose any minimum account balance requirement or low-balance fees on their customers." (para 6, Hong Kong Monetary Authority, 2018)

\section{Virtual bank as a source of financial exclusion}

This rapidly changing technological and regulatory landscape while bringing new opportunities for market competition to reach the remaining unbanked and under-banked in the community, it also creates new challenges by potentially creating new pockets of unbanked groups.

Access to digital financial services is crucial to access the opportunities the internet offers to businesses and customers alike, and hastened by a move to a cashless society, which all by definition requires access to a bank account as well as an ability to understand and use the technology. Therefore, while these technological changes could improve financial inclusion among some, it may at the same time also entrench or create new unbanked or under-banked segments among those who cannot access and use the technology, as the latter will be more and more excluded from the financial system.

Similarly, as the entire banking system, not just virtual banks, embraces technology to improve efficiency and, in many ways, accessibility, it will also come with closures of costly physical branches. This further entrenches a lack of access among those who disproportionately rely on access to physical branches to do their banking, such as the elderly and the disabled.

Generally, the older generation who prefer counter services in traditional banks, as they have a proven track record, and the presence of a physical branch network is a sign of the bank's creditworthiness. Also, customers prefer their money managed by a trusted individual via face-to-face interactions, and virtual banks lack this physical touch. Therefore, even if virtual banks offer significantly lower fees, faster services, and greater convenience, it is still questionable whether these customers have an incentive to switch to them at all. Yet the likely closure of branches will mean they have fewer choices.

Therefore, financial inclusion, while originally focusing on disadvantage and poverty as the driver of exclusion, now also encompasses a wider range of issues including regulatory, ageing and access to and capability with digital technology.

\section{Regulatory considerations in Play}

Existing studies have guided us to possible inclusionary and exclusionary factors of virtual banks, without much definite answers. To further understand its potential impact on financial inclusiveness, extensive context analysis has been conducted to further elaborate and describe the five cores identified by Law and Wong (2021), which are associated with the very existence of virtual bank in Hong Kong.

First is Corporate Governance. Most of the virtual bank has been a joint venture with non-banking groups with a hope to create synergy through building an ecosystem between business users and banking service directly through seamless transaction such as direct payment. So far, it is only a concept and consumers might not have experienced too much difference on the front-end except it has more channel to accumulate or spend points gathered from loyalty scheme. However, there is a potential loophole in terms of governance when banks and non-banks started to have common business interest, but technically non-banks might not be subject to bank regulatory governance. The even closer interplay between these two parties might deserve further scrutiny as it might not be clear how the non-bank would influence the joint venture accordingly. Questions like these could deserve further research. They include: would it create monopoly if customers are restricted from their choices 
due to closely tied loyalty group? Would consumers be burdened with the technology requirements to enjoy these benefits? Would outsiders be restricted to join the ecosystem and hence restrict consumer's choice? Would the market be segmented into different mutually exclusive group and which consumers might ultimately find very difficult to switch between these groups?

Second is technology. Access to technology is another huge concern. The availability, as well as accessibility and affordability of both hardware and software, is assumed given. It is not necessarily the case. Many people living in or near poverty do not have unlimited access to the Internet or the latest model of smartphones. Therefore, backwards compatibility and computing power / data usage are key points to note. There were two surprising concerns that might deserve further scrutiny. First is the continuous update of mobile apps, which results in incompatibility of consumer's older version of the mobile phones, forcing the consumers to buy a new phone to keep up with the latest functions (and hence benefits). Another concern comes from a hypothetical question what if smartphone no longer exists? Will virtual bank cease to exist as well? The over-reliance of smartphone, of which its business is not regulated by any regulatory bodies in Hong Kong, may be a remote concern but its impact would be very great because the phone-makers do have the right to stop producing the device or charge extremely high price once people are addicted to it. It presents a very big loophole and unless virtual banks continue to keep up with the technological advancement of the smartphones, virtual bank could cease to exist. For example, nowadays smartphones are fading out the use of fingerprints and switch to face-recognition technology, and virtual banks have to keep up with the advancement.

Third is the issue of human or personal touch. The basis of trust and confidence have switched from human to non-human. Consumers now look at the screen and in essence they trust the regulators and a mobile app. Concerns arising out of the fact that what if there are problems or issues, could a chat-bot help? Would clients still be able to meet a banker who might give them personal advice based solely on their needs, or would all the clients' need could now be deduced by algorithm? Does it mean that consumers are now only restricted by a very limited range of products which they have no access to view and compare? If there are problems or issues - where can clients go to when there are issues? How to change the habit of consumers hoping to "see the real person" when existing customers in traditional banks are already quite frustrated by calling a hotline but all they got after pressing a number of keys was 10 minutes of music waiting for someone to pick up. Would a robotic chatbot make consumers feel more convenient, or worse?

Fourth is the perception of banks' commitment. It is associated with the perception of apparently low entry cost and exit cost. Whilst respondents do acknowledge very well that it had been extremely difficult to get a banking license, the lack of physical commitment seen by the public had created a perception of low entry cost, but perhaps more importantly the low exit cost. There had been no branch to close, no ATM machine to retrieve, and perhaps no need to send a letter as well. Such perception, admittedly, is not real because of tightened regulatory requirement in the resolution process under the Financial Institution (Resolution) Ordinance, and even if a virtual bank closes the interest of depositors are still well-protected. Yet, it is still apparently way easier for a virtual bank to close than a traditional one. In fact, in one extreme comment from participants, clients feel that their protection is compromised.

Last, but not least, is the issue of Cybersecurity. Based on our findings so far, the public is not educated enough to understand what is going on. A list of issues of cybersecurity has drawn enormous concern as to whether consumers' data will be compromised, what to do with virus attack, or even what to do when they need to change the mobile phone. Take switching mobile phone as an example, a respondent mentioned that originally his phone had one button and that button used to recognise his fingerprint when he logins to his banking apps offered by the traditional apps. When the time he needed to change his phone to a button-less one so he needs to re-do the setting so that his face could be recognised instead of his fingerprints. He is only guided by the phone-sales representative about what to do in case they did use banking apps. The complication was that his phone had more than one apps within the same bank - one for credit card, one for general banking, one for redeeming reward, one for investment, he had to do it many times and it prolonged the time. He switched his phone with a fear of losing access to the bank information since he would not know who to talk to from the bank. In that particular response, the consumers feel very lost and insecure in the process. 


\section{Content Analysis - Regulations on virtual banks in Hong Kong}

There are mainly four documents issued by the HKMA that govern the establishment and definition of virtual bank in Hong Kong, namely: A Revised Guideline on Authorization of Virtual Banks (Hong Kong Monetary Authority, 2018), Minimum criteria for authorization in the Seventh Schedule to the Banking Ordinance (Banking Ordinance, Cap. 155), Guideline on Minimum Criteria for Authorization issued by the HKMA under section 16 (10) of the Banking Ordinance relating to licensing criteria under HKMA (Hong Kong Monetary Authority, 2020a), and Guide to Authorization (in particular Chapter 2 - The Authorization Regime, Chapter 4 Authorization, and Chapter 8 - Application Procedures) (Hong Kong Monetary Authority, 2020b). The virtual bank specified guidelines mainly deal with what defines a virtual bank whilst the ongoing supervision relies on the same set of supervisory requirements applicable to conventional banks. The regulatory framework is formed by four key regulators, namely the HKMA, Securities and Futures Commission, Mandatory Provident Funds Authority, and Insurance Authority. There are supervisory policy manuals, guidelines, circulars issued by these regulators describing the regulatory expectation to banks and bank activities, as well as ordinance and case law.

It has been argued that it is problematic to supervise virtual bank the same way as conventional banks through replicating existing rules and regulations due to the technological aspects and different business models associated with virtual bank operation (Lee, 2021). The following content analysis will illustrate the potential gaps. To illustrate these gaps, House of Common Briefing Paper issued in the UK will also be addressed and contrasted with the rules in Hong Kong.

Guideline on Minimum Criteria for Authorization has firmly requested that virtual banks should follow the same standard in terms of customer protection, it is stated, in para 21, that:

"A virtual bank should treat its customers fairly and adhere to the Treat Customers Fairly Charter...." (para 21, Hong Kong Monetary Authority, 2020a).

It would be essential to examine whether Treat Customers Fairly Charter would be executable by the virtual bank. There are 5 principles whereas Principle 5 stated:

"Banks in Hong Kong that engage in mass retail market should provide reasonable access to basic banking services to members of the public, paying special attention to the needs of vulnerable groups. Recognizing that consumers also have their responsibilities, banks should join force with government, regulatory bodies and other stakeholders in financial education to promote financial literacy.” (Emphasis added) (Principle 5, Hong Kong Monetary Authority, 2014)

In association with treating customer, Principle 5 of Treat Customers Fairly Charter is unlikely to be comprehensive if banks only have an obligation to promote financial literacy. In virtual bank, clients do need to have a good level of technical literacy to comprehend with the operation and function offered by the bank through smartphones. Whilst virtual bank seems to have obligation to take care of their own technology risk (para 14-15, Hong Kong Monetary Authority, 2018), but it does not impose any requirement to explain or educate to the public of what technology is involved. It is contrary with the need to educate the public on the investment products sold to the investors. Direct adoption of the Treat Customers Fairly Charter may not be sufficient in terms of treating customers fairly if virtual banks do not need to ensure good level of technical literacy relating to the virtual bank operation.

Minimum Criteria for Authorization stated that to authorize a bank, Monetary Authority must be satisfied with the minimum criteria as summarized (Hong Kong Monetary Authority, 2020a):

- Para 2 : adequate home supervision (if incorporated outside Hong Kong)

- Para 3 : identity of controllers

- Para 4\&5 : fitness and propriety of directors, controllers, chief executives and executive officers

- Para 5A : adequate systems of control for appointment of managers

- Para 6 : adequate financial resources 
- $\quad$ Para 7 : requirement for adequate liquidity

- Para 8 : adequate control of large exposures

- Para 9 : requirement to maintain adequate provisions

- Para 10 : requirement to maintain adequate accounting systems and adequate systems of control

- Para 11 : requirement to make adequate disclosure of information

- Para 12 : business to be conducted with integrity, prudence, and competence

It is notable that there appears to be an absence of fulfilling the technical requirement in operating virtual banks, particularly in terms of handling cybersecurity risk and appointing the right personnel who is "fit and proper" under section 71 of Banking Ordinance to manage the bank operation highly driven by use of technology from the clients' side. Similarly, the regulations on virtual banks have not addressed the technical side to operate the virtual bank. It has relied on the virtual banks alone to convince regulators that they could cater such. However, it is unclear whether the regulators would have the expertise to assess whether a virtual bank is fit for operating without physical branches, at least not in the eyes of the public. For example, would the regulators be able to decide whether a virtual bank is technically capable of running a virtual bank, and whether such decisions might have been outsourced to an external consultant is unknown.

\section{House of Commons Briefing Paper}

To relate these potential regulatory gaps to financial inclusion, it might be helpful to refer to the UK experience where the House of Commons Briefing Paper has addressed the issues of exclusionary factors arising out of the use of digitization (House of Common Briefing Paper, 2017).

\section{Digital Exclusion}

35. The growth of internet banking has meant an increasing number of financial services are moving online. While this has made banking more convenient and accessible to some, others face the negative effects of increasing bank closures and isolation from digital platforms. 53\% of UK bank branches closed between 1989 and 2016.

36. Digital exclusion can affect those who are excluded from digital services due to high cost, capability issues or limited geographical access; 12 million people live in rural or remote areas of the UK where poor internet access can make managing money online a difficult task.

37.The ageing population is also at risk. Just $53 \%$ of single pensioners had internet access in 2016 and $93 \%$ of those aged 80 and over do not use internet banking.

38. Non-internet users are likely to miss out on competitive online deals and instant, easy access to their accounts and services.

\section{Self-exclusion}

44. Finally, a proportion of individuals are 'self-excluded' either through their own choice or a lack of awareness of the services available to them....

45. Beyond a lack of awareness of the services on offer, there are a number of other reasons for self-exclusion. These can include:

- A lack of financial capability and confidence;

- Lack of trust in providers;

- Psychological barriers; and

- An inability to access products via the preferred channel.

The report has illustrated that exclusionary factors could also be driven by digital advancement that leads to selfexclusion. The usual financial inclusion caused such as outright refusal by banks or lack of credit due to financial strength might not explain the current situation featured mainly by a mismatch between potential customers' needs 
and the products offered by banks. It could be further illustrated in the UK Financial Inclusion Report 2019-2020 (Department for Work and Pensions, 2020) which the following inclusion factors have been explored.

- Access to banking via face-to-face services continues to be an important channel for many customers, although COVID-19 pandemic has accelerated the use of digital banking.

- Access to cash remains important.

- Access to financial products including affordable credit, non-interest loan, prize-linked savings scheme.

- Allowing credit unions to offer a wider range of products and services.

- The use of dormant assets.

- Strategic Fintech Review and roll out of Open Banking.

- Money and Pensions Services (MaPS) in January 2019 and simplified the existing public financial guidance landscape.

- The role of the government in supporting consumers in financial difficulty.

Comparing the UK Financial Inclusion Report 2019-2020 with the relevant guidelines issued by the HKMA indicates an insufficient length to address the self-exclusionary factors due to concern from technical literacy. For example: the Guideline on Banking Services for Persons with Intellectual Disabilities of Hong Kong Association of Banks (Hong Kong Monetary Authority, 2020c), there are generic guidelines to mention that banks are reminded that in providing banking services to members of the public they should also pay special attention to customers in need. There is no specific mention of which kind of special attention to be addressed and they might have missed the chance of requesting the bank to ensure a good level of technical or AI literacy of the public; In "Feedback from Thematic Review of AIs' Application of AML/CFT Controls in the SME Segment" (Hong Kong Monetary Authority, 2019a), it only focuses on technology-neutral approach to conduct customer risk assessment, customer due diligence, implementation and training on money laundering and terrorist financing risk measures, the use of technology neutral approach involving mainly remote onboarding. In De-risking and Financial Inclusion (Hong Kong Monetary Authority, 2016), it concerns with difficulty in opening bank account for Small and Medium Enterprise but has not been explicit in addressing how technology would address this issue.

The above guidelines appear to be less sufficient to cover what is needed for virtual banking. It further illustrates that the existing regulation of conventional bank should have been extended in order to address the impact of technology that on virtual banks. In the short term, the regulatory measures should be further imposed and broadened to address technology risk of banks and AI/technical literacy of customers. For example, Guide to Authorization should include requirement on technology and impose measures to monitor customers' comprehensiveness. The Treat Customers Fairly Charter shall require the bank to contribute not only on financial literacy, but also technological/digital literacy. A code of conduct of virtual bank of its own should be established addressing their duties to promote AI or technical literacy. Furthermore, conventional banks should also be governed in response to their possible change in business strategies considering bank digitization process whilst their reliance on virtual space has been increasing.

\section{Recommendations: a direction for future regulation}

Beside the content of the guidelines, public interest to promote financial inclusiveness should be incorporated into virtual banking regulation, there are three recommendations for regulatory bodies as well as banks to overcome the issues identified in this paper and to improve accessibility and promote financial inclusion overall. These recommendations aim to improve public comprehensiveness and accessibility, in order to promote financial inclusiveness in the background of the absence of regulatory framework specifically for the virtual bank.

a) The revised bank-customer relationship

First is to review and accommodate the changes in the bank-customer relationship under the new interaction model. 
Online and Face-to-face relationships are different. Both banks and customers might no longer see each other physically. It implies a fundamental change of the role of a bank and its bankers, presumably from a human being to an algorithm in most of circumstances. The interaction and communication between the bank and clients are different in the following two scenarios: the first scenario is when the clients made an enquiry to the bank, how we could ensure the bank has "listened" to the clients' need, or have we, in the second scenario, asked the bank to restrict the questions customers could ask to ensure the chatbot could respond accordingly. With the change of personal touch from face-to-face interaction to customers touching the screen, the conventional thinking of "treating the customers fairly" might no longer mean the same, for example, the principle 5 of "ensuring access to bank" might not mean "to ensure the provision of accessibility ramp for the clients on wheelchair to enter the branch", instead it could mean "to ensure customers are well-equipped to know how to use their apps".

\section{b) Comprehensiveness of new bank operation}

Second is to enhance transparency and disclosure of the technology involved in virtual bank operation which links directly to customers' comprehensiveness of the bank operation.

When clients follow up with some sort of application or dispute, instead of having a bank staff for the clients to inquire about the progress or even push forward the application, bank customers would need to look at the screen and see the report. The fact that traditional bank and virtual bank do not operate the same ways, and they have different channels to attract, retain and serve customers. Their coverage and available channels to maintain the coverage is different. It would be important to ensure the banks continue to assure transparency and responsiveness with bank clients. Also, virtual banks would, at least in the short term, still rely on the traditional bank (for example, for cash transfer and withdrawal), so it is undesirable if regulatory framework does not place sufficient emphasis to govern the operation between traditional bank and virtual bank, and more importantly to request such framework to be known and easily comprehensible by bank clients.

c) Promoting financial inclusion of the vulnerable group

Third is to provide greater assistance to customers to aid their comprehensiveness of the increasingly complex virtual bank operation, particularly for those who do not have high financial literacy and those who might be further discouraged to make an enquiry due to lack of human interaction with the banks.

To prevent the self-exclusion, the need to offer greater assistance to customers becomes extremely critical. For example, as explained in a Briefing paper from House of Commons in the UK (House of Commons Briefing Paper 2017), groups such as the homeless, refugees, and the low-income group might still be excluded from the new virtual bank space. The UK Financial report starts to pay closer attention to the impact of FinTech although not directly addressed to the virtual bank (pp 23-25, Department for Work and Pensions, 2020). Hong Kong Regulator should monitor financial inclusion by supervisory existing banking practices and services as well as collecting subjective view form the public, especially the vulnerable groups. By building the awareness of its availability, further lobbying should be made to improve the capability and confidence of bank clients, to make known who such providers are, to build trust not only to banks but those who offer critical services to clients, to remove psychological barriers of the technological advances ahead, to offer more access for those without smartphones as well.

\section{Conclusion}

Virtual bank could further promote financial inclusions through acknowledging its difference with the conventional bank. This case study leads to a few recommendations for the regulators to amend existing guidelines to address technological feature of the virtual bank, review and accommodate the differences in the bank-customer relationship under the new interaction model, enhance transparency and disclosure of the technology involved in virtual bank operation; provide greater assistance to customers to help them understand virtual bank better. The focus of these recommendation is to improve accessibility and make further impact to financial inclusion. This study is limited by lack of empirical findings, which should be further researched especially on clients' 
technological literacy and expectation on virtual bank both locally and internationally to further assist virtual bank and regulators to offer banking services that could fit clients' needs, wherever they are.

Acknowledgement: I am grateful to Liliana Lopa of her guidance in publishing this article. I am also obliged to Mr. Davyd Wong for his helpful insights.

Funding: self-funded.

Author contribution: conceptualization, Sau-Wai Law; data curation, Sau-Wai Law; formal analysis, Sau-Wai Law; funding acquisition, Sau-Wai Law; investigation, Sau-Wai Law; methodology, Sau-Wai Law; project administration, Sau-Wai Law; resources, Sau-Wai Law; software, Sau-Wai Law; supervision, Sau-Wai Law; validation, Sau-Wai Law; visualization, Sau-Wai Law; writing - original draft, Sau-Wai Law; writing - review \& editing, Sau-Wai Law.

About the author: Sau-Wai Law (Samuel) is a Senior Lecturer in the Department of Law and Business at Hong Kong Shue Yan University. Before joining Shue Yan University in January 2021, he had over 14 years of banking experience in Hong Kong, taking up various roles as a credit risk manager, private banker, and strategic planning specialist. He is a PhD candidate at Faculty of Law at HKU with research focus on banking and finance law, contract law, and arbitration and dispute resolution. Samuel can be contacted at: swlaw@hksyu.edu.

\section{References}

1. Department for Work and Pensions (2020). UK Financial Inclusion Report 2019-2020. Available at: [Link]. (accessed: 28 $8^{\text {th }}$ June 2021).

2. Gov.uk (2017). Government response to Lords Select Committee final report on financial exclusion. Cm 9524, Nov 2017. Available at: [Link】 (accessed: 1 Sep 2021).

3. HKSAR (2019). The Hong Kong Poverty Situation Report 2019. Available at: [Link] (Accessed: 13 August 2021).

4. Hong Kong Monetary Authority (2014). Treat Customers Fairly Charter, 28 March 2014, HKMA. [Link] (accessed: 14 September 2021).

5. Hong Kong Monetary Authority (2016). De-risking and Financial Inclusion, HKMA. [Google Scholar] (accessed: 3 August 2021).

6. Hong Kong Monetary Authority (2018). A revised Guideline on Authorization of Virtual Banks, Issued on 30 May 2018. [Google Scholar] (accessed: 26th June 2021).

7. Hong Kong Monetary Authority (2019a). Feedback from Thematic Review of AIs' Application of AML/CFT Controls in the SME Segment", 14 June 2019, Hong Kong Monetary Authority. [Google Scholar] (accessed: 3 August 2021).

8. Hong Kong Monetary Authority (2019b). Granting of virtual banking licences, 27 Mar 2019 HKMA Speech. Available at: [Link] (accessed: 12 August 2021).

9. Hong Kong Monetary Authority (2019c). Keynote Speech at the HKAB \& HKIB Distinguished Speaker Luncheon Norman T.L. Chan, Chief Executive, 26 Sep 2019 Hong Kong Monetary Authority. Available at: [Link] (accessed: 1 September 2021).

10. Hong Kong Monetary Authority (2020a). Guideline on Minimum Criteria for Authorization” issued by the HKMA under section 16(10) of the Banking Ordinance. Available at: [Link] (accessed: 26th June 2021).

11. Hong Kong Monetary Authority (2020b. Guide to Authorization”, HKMA. Available at: [Link] (accessed: 26th June 2021).

12. Hong Kong Monetary Authority (2020c). Guideline on Banking Services for Persons with Intellectual Disabilities of Hong Kong Association of Banks”, HKMA. Available at: [Link] (accessed: 3 August 2021).

13. Hong Kong Monetary Authority (2021). Virtual Bank. Available at: [Link] (accessed: 12 August 2021).

14. House of Commons Briefing Paper (2017). Financial Inclusion (Exclusion)"] (15 December 2017) at 4, available at: [Link] (accessed: 13 August 2021).

15. Law S.W. and Wong D. Could increasing regulatory focus realise the Inclusive Potential of Virtual Banks? pp. 38-43. Banking Today. Available at: [Link] (accessed: 11 August 2021). 
16. Lee, E. (2021). Digital Financial Inclusion: Observations and Insights from Hong Kong's Virtual Banks. Law and Contemporary Problems, 84(1), 95-113. [Google Scholar].

17. Park, C. Y., \& Mercado, R. (2015). Financial inclusion, poverty, and income inequality in developing Asia. Asian Development Bank Economics Working Paper Series, (426). [Google Scholar] (accessed: 1 September 2021).

18. Sustainable Development Goal (2021). Take Action for the Sustainable Development Goal: The United Nations. Available at: [Link] (accessed: 12 August 2021).

19. The World Bank (2017). The Global Findex Database, The World Bank group. Available at: [Link] (accessed: 13 August 2021).

20. The World Bank (2021). Financial Inclusion. Available at: [Link] (accessed: 13 August 2021).

21. UNCDF (2021). Financial Inclusion and the SDGs. Available at: [Link] (accessed: 13 August 2021). 